\title{
CONSCIÊNCIA DE CLASSE E PARTIDO OPERÁRIO: ALGUNS APONTAMENTOS DA ANÁLISE DE GEORGE LUKÁCS E ROSA LUXEMBURGo
}

\author{
Gustavo Casasanta Firmino ${ }^{1}$
}

\begin{abstract}
Resumo
0 artigo pretende debater a sempre polêmica questão que gira em torno do marxismo, no que concerne à formação política da consciência de classe. Será tal consciência fruto da posição que a classe trabalhadora possui dentro do quadro estrutural, de uma dada sociedade, em determinado modo de produção e tempo histórico; ou antes, a consciência de classe somente pode ser pensada, quando construída teoricamente e advinda "de fora" da classe operária, por uma vanguarda partidária portadora da teoria? No limite, a primeira posição foi, por muitas vezes, denominada "espontaneísta" em contraposição à segunda, por vezes identificada enquanto "vanguardista". Para avançar do ponto de vista teórico e histórico nessa discussão, procurando superar a forma dicotômica de abordagem do tema, estabelecemos um diálogo com algumas das leituras feitas por Rosa Luxemburgo (1871-1919) e George Lukács (1885-1970), duas grandes referências teórico-políticas acerca da discussão proposta.
\end{abstract}

Palavras chave: George Lukács. Rosa Luxemburgo. Consciência de classe. Organização política.

${ }^{1}$ Mestrando em Ciências Sociais, Universidade Estadual de Londrina. gcasasanta@hotmail.com 


\title{
Class CONSCIOUSNESS AND WORKERS PARTY: SOME NOTES ON THE ANALYSIS OF GEORg LUKÁCS AND RosA LUXEMBURG
}

\begin{abstract}
This paper intends to debate the usual polemic issue around Marxism, related to the political formation of class consciousness. Would such consciousness be the result of the working class position in the structural frame of a given society in a determined mode of production and historical moment, or beforehand, the class consciousness (a consciousness which, embracing the whole production relations, might lead to an effective change on the social relations) might be only thought, when theoretically built and coming from "outside" the working class, by a vanguard party bearer of the theory? On the edge, the first position was, several times, nominated "spontaneist", versus the second one, seldom identified as "avant-garde". To move forward from the theoretical and historical point of view on this discussion, looking to overcome the dichotomous method of approaching the theme, we established a dialogue with some lectures given by Rosa Luxemburg (1871-1919) and Georg Lukács (1885-1970), two great theoretical-political references on the proposed discussion.
\end{abstract}

Keywords: George Lukács. Rosa Luxemburgo. Class consciousness. Political organization.

Não é a consciência do homem que lhe determina o ser, mas ao contrário, o seu ser social que lhe determina a consciência (Karl Marx).

$\mathrm{H}$ á tempos tem sido um campo comum de discussão dentro do marxismo a relação entre classe social e consciência de classe, a saber: como ocorre o processo de formação da consciência de classe? Tal processo ocorre de maneira "espontânea", visto que as classes sociais estão dadas no campo econômico e inseridas em relações de produção antagônicas, desiguais e materialmente estabelecidas; ou então, será o processo de formação dessa consciência classista algo "não natural", que não pode ser fornecida - para se pensar numa mudança estrutural dos quadros de exploração, numa revolução - a partir da classe explorada visto que, ideologicamente, essa mesma classe é limitada pela assimilação "não consciente" do status quo vigente? 
Para Marx, a classe social seriaformada, simultaneamente, por dois aspectos distintos, um objetivo e o outro subjetivo. 0 aspecto objetivo refere-se à posição real segundo a qual a classe esta objetivamente (materialmente) posta no terreno das relações sociais, na medida em que desempenha de fato uma determinada função na (re)produção das relações sociais. 0 segundo aspecto, diz respeito às formas de compreensão da realidade sob uma base material específica, ou seja, refere-se ao condicionamento de interesses específicos, políticos (de classe) a partir de um terreno comum a todos os agentes de determinada classe social, a saber, o campo da produção. Importa-nos compreender, portanto, que da existência material de uma classe, não se transita imediatamente à luta de classes - que pressupõe a luta aberta de determinada classe na defesa de interesses específicos. Parece-nos assim, bastante ilustrativa a seguinte passagem de 0 Dezoito Brumário de Luís Bonaparte, na qual Marx se refere ao papel desempenhado pelo campesinato na França de Luís Bonaparte:

Na medida em que milhões de famílias vivem em condições econômicas que as separam umas das outras, e opõem seu modo de vida, os seus interesses e sua cultura aos das outras classes da sociedade, estes milhões constituem uma classe. Mas na medida em que existe entre os pequenos camponeses apenas uma ligação local e em que a similitude de seus interesses não cria entre eles comunidade alguma, ligação nacional alguma, nem organização política, nessa exata medida não constituem uma classe (MARX, 1978, p. 397).

Segundo Duarte Pereira (2003, p. 228-229), Marx e Engels teriam considerado que o desenvolvimento do modo de produção capitalista acirraria, cada vez mais, os embates entre capital e trabalho, de modo que as contradições objetivas sob as quais se desenvolve o capitalismo levariam ao enlace de choques individuais entre burguesia e proletariado, que segundo a dinâmica das mesmas contradições se coletivizariam, articulando-se então reivindicações tanto no plano econômico quanto no político. Desse modo, a classe operária:

[...] instruída por suas experiências práticas e apoiada em sua consciência espontânea - dilacerada pela superestrutura político-cultural e os infortúnios infligidos pela base econômica -, a classe proletária avança em sua unidade e organização, arrebatando, ainda sob o regime capitalista, melhores salários, condições de trabalho mais favoráveis e direitos políticos, como o sufrágio ou a liberdade de organização sindical e partidária (PEREIRA, 2003, p. 228). 
Contudo, considera o autor que na visão marxiana, a constituição da classe operária não estará concluída, de fato, enquanto o proletariado não romper com possíveis visões "parcelares" e "imediatas" no tocante a sua condição de classe explorada, e se unir em torno de um programa político socialista que, abarcando toda a realidade social, proponha-se a superar a lógica de (re)produção capitalista, superando a própria lógica de uma sociedade classista. Portanto, pensar (enquanto classe) no rompimento do reprodutivismo de relações sociais antagônicas demandaria, além da consciência imediatamente "espontânea" fornecida pelo afloramento de condições materiais antagônicas, a elaboração de um projeto político que ultrapasse essa forma de consciência imediata. Mas, de que forma e em que medida o agir conscientemente revolucionário do proletariado, enquanto classe poderia ser pensado? Aqui começa nossa discussão.

São sempre clássicas as formulações de Lenin sobre o papel do partido de classe diante dos episódios revolucionários, no tocante à formulação de bandeiras de luta e da organização das massas em torno de um projeto político comum. Nesse sentido, interessa saber que Lenin compreendia o partido como dividido em três eixos centrais, em ordem crescente de importância: organização, estratégia e programa, com uma clara divisão do trabalho entre a base (militantes) e a executiva partidária (vanguarda), numa forma de organização partidária semelhante à de empresas capitalistas: com um núcleo bastante diminuto e melhor remunerado que fixaria, de antemão, um programa a ser seguido (CARDOSO, 2007, p. 8).

De acordo com Duarte Pereira (2003, p. 232-233), o pensamento de Lenin é herdeiro das concepções político-revolucionárias da Segunda Internacional Comunista, de modo que em concordância com Kautsky, aquele concebera que a "consciência espontânea" do proletariado (a que lhe é dada pela posição ocupada na produção) não conduziria ao socialismo, de tal modo que seria necessária uma teorização científica advinda "de fora" da classe trabalhadora, de uma vanguarda política: o partido. Formulações dessa ordem foram por vezes denunciadas como "autoritárias" ou "vanguardistas" por conceber a ação política a partir de uma organização centralizada e de programas partidários definidos por uma cúpula dirigente.

Na contramão do "centralismo" de Lenin e Kautsky, Rosa Luxemburgo parte de uma concepção política na qual a ação espontânea e "livre" das massas se encontra num primeiro plano de análise. Em que, pese o papel dos teóricos de partido, da intelligentsia operária, do setor mais politizado da classe na 
educação política do proletariado, a autora considera que o papel da "vanguarda" é secundário em relação ao das massas. Essa concepção aparece de forma bastante enfática na sua obra Greve de Massas Partido e Sindicatos (1906), na qual estuda o movimento das greves operárias na Rússia, em 1905, que tendo começado a partir de reivindicações econômicas imediatas de "direitos" no terreno da produção (melhoria das condições de trabalho, salários mais justos, diminuição da jornada de diária, etc.), rapidamente evoluíram para reivindicações políticas que exigiam a liberdade de reunião pública, a associação dos trabalhadores em sindicatos livres, o sufrágio universal, etc.

Para Luxemburgo, a consciência de classe se funda na ação direta das massas contra a ordem estabelecida, na espontaneidade, na "ação criadora e livre" do proletariado. Analisando o processo histórico da Revolução Russa de 1905, formulou que:

A concepção rígida e mecânica da burocracia só admite a luta como resultado da organização que atinja um certo grau de força. Pelo contrário, a revolução dialética, viva, faz nascer a organização como produto da luta. Vimos já um exemplo magnífico deste fenômeno na Rússia, onde um proletariado quase desorganizado começou a criar uma vasta rede de organizações depois de um ano e meio de lutas revolucionárias tumultuosas (LUXEMBURG0, 1974, p. 76).

$\mathrm{Na}$ brochura de Rosa Luxemburgo expressões como "sentimento do proletariado" e "instinto de classe" (LUXEMBURG0, 1974, p. 78) muitas vezes se fazem presentes, de modo que Greve de Massas por vezes foi considerada por seus críticos como sendo a "Bíblia do espontaneísmo", ao supervalorizar os fatores objetivos da história e subestimar o papel do partido, de uma vanguarda. Esse seria o principal traço do que, posteriormente, ficou conhecido como "luxemburguismo"2 (LOUREIR0, 1997, p. 47).

George Lukács, em sua mais importante obra de juventude História e Consciência de Classe (1923), segue, em grande medida a concepção leniniana a respeito do papel do partido em relação às classes sociais e em relação à formação da consciência de classe, a partir de uma vanguarda proletária consciente. Aqui 0 ponto de partida de Lukács é a denuncia da "antinomia burguesa" que, no limite, apenas é capaz de considerar a realidade a partir da perspectiva individual, não

\footnotetext{
${ }^{2}$ Segundo Loureiro (2004, p. 154), foi Lukács quem, pela primeira vez, sintetizou teoricamente e de maneira refinada o que posteriormente, na época de Stalin, foi denominado luxemburguismo - uma prática política equívoca, baseada em uma teoria organicista do desenvolvimento histórico.
} 
levando em conta 0 aspecto dialético e estrutural do desenvolvimento histórico e não considerando a realidade a partir da totalidade das relações sociais, o que determinaria em grande medida a aversão da consciência burguesa reificada (presente inclusive em setores do proletariado) a um programa político revolucionário.

0 ponto de vista da totalidade não determina, todavia, somente 0 objeto, determina também o sujeito do conhecimento. A ciência burguesa - de maneira consciente ou inconsciente, ingênua ou sublimada - considera os fenômenos sociais sempre do ponto de vista do indivíduo. E o ponto de vista do indivíduo não pode levar a nenhuma totalidade, quando muito pode levar a aspectos de um domínio parcial, mas na maioria das vezes somente a algo fragmentário: a "fatos" desconexos ou a leis parciais abstratas. A totalidade só pode ser determinada se o sujeito que a determina é ele mesmo uma totalidade; e se o sujeito deseja compreender a si mesmo, ele tem de pensar 0 objeto como totalidade. Somente as classes representam esse ponto de vista da totalidade como sujeito na sociedade moderna (LUKÁCS, 2003a, p. 107).

Lukács fará um elogio à concepção de totalidade presente na obra de Rosa Luxemburgo, intitulada A acumulação do capital (1896), segundo ele, a mais importante da autora. Para o filósofo húngaro, foi um grande mérito da obra de Luxemburgo ter realizado a ligação dialética entre teoria política e práxis revolucionária, visto que, para o marxismo, o reconhecimento teórico do caráter historicamente limitado do capitalismo (no que se refere à questão da acumulação) pode fazer com que desponte a necessidade consciente da revolução social - uma transformação total da totalidade social (LUKÁCS, 2003a, p. 125).

Entretanto, em ensaio crítico da obra A Revolução Russa (1917) - na que o tom marcante da discussão levantada por Rosa Luxemburgo é a crítica à prática política "centralista" adotada pelos bolcheviques na Rússia pós-revolucionária Lukács teceria uma crítica à concepção de que a compreensão dessa totalidade das relações sociais poderia se dar de maneira espontânea à classe proletária (segundo ele, entendida por Luxemburgo como uma "totalidade orgânica"). Em Lukács, faz-se necessário que o Partido Comunista (nesse entendimento, o portador da teoria científica) dirigisse e coordenasse a revolução, levando ao proletariado a verdadeira consciência de classe, a consciência entendida enquanto totalidade dialética do processo histórico, pois: "[...] o caráter processual e dialético da consciência de classe, transforma-se, na teoria do partido, em dialética 
conscientemente manipulada" (LUKÁCS, 2003c, p. 575-576), ou ainda: "0 Partido Comunista é uma forma autônoma da consciência de classe do proletariado que serve ao interesse da revolução"3 (LUKÁCS, 2003c p. 579).

Ademais, Lukács criticou Luxemburgo por ter superestimado o papel do proletariado (em sua força e consciência revolucionária), o que condicionou a uma subestimação, no processo da revolução, do papel de vanguarda do Partido Comunista. Portanto, a questão equivocada na crítica luxemburguiana à política bolchevique estaria fundada, ao mesmo tempo, numa exagerada valoração do lugar no qual o proletariado está inserido na sociedade (que o tornaria potencialmente revolucionário), em detrimento da ação política consciente da vanguarda partidária (LUKÁCS, 2003b, p. 493). Lukács atribuiu a Luxemburgo uma visão organicista do processo revolucionário, por sobrevalorizar 0 desenvolvimento contraditório das forças produtivas como fator elementar à revolução. Segundo o próprio Lukács: "Trata-se da superestimação do caráter orgânico do desenvolvimento histórico" (LUKÁCS, 2003b, p. 497). Para o autor, nessa concepção:

0 verdadeiro princípio revolucionário deve ser buscado exclusivamente na espontaneidade elementar das massas. Em relação a elas, as organizações partidárias centralizadas têm sempre uma função conservadora e de entrave. Acredita que, no caso de uma centralização efetivamente implementada,

\footnotetext{
${ }^{3}$ Antes de avançarmos na crítica ao modo como Lukács teorizou a relação entre classe e partido em História e Consciência de Classe (1923), cabe assinalar também a riquíssima auto-crítica feita pelo autor no prefácio à reedição daquela obra, em 1967. Na ocasião, Lukács indicou que suas posições intelectuais no período da primeira edição da obra mencionada herdaram, ao mesmo tempo, um messianismo e utopismo político (embalados pelo sectarismo revolucionário radical dos anos 1920) e um idealismo filosófico (balizado pela categoria hegeliana do sujeito-objeto idêntico) que em parte caracterizaram os fundamentos intelectuais de sua produção intelectual no período de 1917-1924. 0 grande problema conceitual da classe operária enquanto sujeito-objeto idêntico da verdadeira história da humanidade não levaria em conta a dialética materialista, mas antes, uma problemática essencialmente idealista ao identificar toda forma de objetivação humana no mundo como alienação (LUKÁCS, 2003d, p. 26). Dessa postura hegeliana da qual Lukács adverte expressamente o leitor no prefácio à edição de 1967, resultaria, em grande medida, o tratamento dado pelo autor à questão da relação de vanguarda do partido em relação à classe operária, uma vez que, armado teoricamente, o partido (um elemento exterior à luta de classes objetivada dos trabalhadores/luta econômica imediata) seria capaz de fornecer ao proletariado uma compreensão "correta" (a partir da perspectiva de totalidade, superando assim, uma primeira percepção parcelar/trade-unionista de classe) em relação aos rumos da revolução socialista.
} 
apenas se intensificaria a "cisão entre as massas tempestuosas e a social democracia hesitante". Em segundo lugar, porque considera a própria forma de organização como algo que "se desenvolve" e não como algo que é "feito" (LUKÁCS, 2003b, p. 509).

É importante destacar que a argumentação de Lukács acerca da teoria luxemburguiana referente à relação das massas com o partido padece de alguns equívocos e imprecisões. Em primeiro lugar, para Luxemburgo, o partido político exerce um papel importante durante a revolução. Por exemplo, a autora considerou que a sublevação proletária em 1905 teve como importante fundamento os anos de propaganda do partido social-democrata russo em meio às massas, o que em grande medida permitiu a passagem de reivindicações puramente econômicas para reivindicações políticas (LUXEMBURG0, 1974, p. 33). Outro exemplo, que poderia ser extraído da revolução de 1917, é o fato de a autora ter elogiado 0 partido bolchevique por ter sido o único que compreendeu as tarefas de um partido "verdadeiramente revolucionário", o que pôde garantir o curso da revolução (LUXEMBURG0, 1991a, p. 71). No que diz respeito à segunda crítica, de fato, em Rosa Luxemburgo a organização partidária é algo pensado a posteriori, por se considerar, grosso modo, que a consciência de classe é algo apreendido na luta de classes real da classe trabalhadora, em uma relação de recíproca aprendizagem com o partido.

A concepção relacional entre o partido (entendido como portador da teoria científica) e a classe (o sujeito revolucionário real do processo histórico), em uma relação de interdependência contínua na que, entretanto, o partido ocupa um lugar secundário diante da classe trabalhadora atravessa toda a composição teórica luxemburguiana. Na obra A Revolução Russa a questão é colocada da seguinte forma:

[...] nenhum programa socialista, nenhum manual de socialismo podem indicar de que tipo serão as milhares de medidas concretas, práticas, grandes e pequenas, que é preciso tomar a cada passo para introduzir os princípios socialistas na economia, no direito, em todas as relações sociais. Não é uma lacuna mas, ao contrário, é precisamente a vantagem do socialismo científico sobre o utópico (LUXEMBURG0, 1991a, p. 92).

0 trecho acima citado se relaciona diretamente à crítica feita por Rosa Luxemburgo aos dirigentes bolcheviques que, segundo a autora, após a tomada do poder em 1917, cometeram um grave erro ao reprimir os mais diversos direitos 
democráticos essenciais para a construção do socialismo como a liberdade de associação e reunião, de imprensa, e até mesmo a Assembléia Constituinte, em nome do que se denominou "ditadura do proletariado". Considera Luxemburgo, que ao estabelecer uma oposição entre democracia e ditadura, os bolcheviques teriam incorrido em um grave erro, visto que a democracia seria condição sine qua non para se pensar a única via para a construção de uma sociedade socialista. Para Luxemburgo, a ditadura do proletariado: "consiste na maneira de aplicar a democracia, não na sua supressão" (LUXEMBURG0, 1991a, p. 96). Loureiro sintetiza de forma precisa a polêmica da autora travada com os bolcheviques, no que diz respeito à constituição da ditadura proletária em A Revolução Russa:

[...] a realização do socialismo exige democracia, isto é, "vida política das massas", "ativa", "enérgica" - "a única fonte viva a partir da qual podem ser corrigidas as insuficiências congênitas das instituições sociais" (LUXEMBURG0, 1991a, p. 87-88) - "vida pública", "fonte da experiência política", "opinião pública", "espaço público" (LuXEMBURGO, 1991a, p. 93), liberdades democráticas. 0 que, na situação concreta da Rússia, em fins de 1917, significava sovietes como espinha dorsal, mais Constituinte e sufrágio universal (ibidem, p. 90) (LOUREIR0, 1997, p. 52).

Por sua vez, Lukács irá entender que a questão da "liberdade" enquanto totalidade social reside precisamente no partido. Considera que o Partido Comunista, em oposição aos partidos burgueses, é a forma conscientemente organizada pela qual o proletariado daria o primeiro salto consciente para 0 verdadeiro reino da liberdade. Por liberdade, complementa o autor, não se entende a liberdade individual no sentido estritamente burguês e limitado (parcelar) em relação à totalidade (LUKÁCS, 2003c, p. 554-555). A verdadeira liberdade estaria para além da concepção individualista burguesa, posto que a mesma desemboca, necessariamente, na falta de liberdade de outrem. Em Lukács, a condição para se romper com o princípio corruptor da liberdade burguesa reside na renúncia à liberdade individual, em detrimento de uma "vontade conjunta" essencialmente comunista e interessada, de fato, em conquistar a verdadeira liberdade. "Essa vontade conjunta e consciente é o Partido Comunista" (LUKÁCS, 2003c, p. 556).

Para além do fato do Partido Comunista ser o portador da compreensão da realidade enquanto totalidade, outro fator que o distinguiria dos partidos burgueses seria o princípio da disciplina partidária que aparece enquanto forma organizativa fundamental na que, pela mediação consciente da organização 
partidária, a classe trabalhadora poderia conquistar a verdadeira liberdade. "Qualquer partido comunista representa, por essência, um tipo superior de organização a todo partido burguês ou partido operário comunista. É o que se deduz pelas rigorosas exigências feitas aos seus membros individuais" (LUKÁCS, 2003c, p. 557).

Em História e Consciência de Classe, Lukács operou todo um esforço teórico no sentido de pensar a realidade das relações sociais entre as classes no plano da totalidade, em que, segundo o autor, residiria precisamente o mérito da análise luxemburguiana presente, por exemplo, em A Acumulação do Capital. Não obstante, mesmo considerando equivocadas as análises de Luxemburgo em A Revolução Russa, não deixa de reconhecer na autora uma "grande dialética" (LUKÁCS, 2003b, p. 499).

Contudo, a nosso ver, o grande problema da linha de análise de Lukács reside no fato do autor considerar o Partido Comunista enquanto o único portador da verdadeira consciência de classe, aquele que de fato encarna em si a compreensão da realidade enquanto totalidade. Ao aceitar esse pressuposto, a questão das chamadas "liberdades democráticas" passa a aparecer de fato, na crítica dirigida a Luxemburgo, como uma não-questão. Como vimos, o primeiro passo para a conquista da verdadeira liberdade, residiria na disciplina absoluta dos indivíduos ao partido, a um programa político comum. Na visão do autor, poderíamos inferir que a questão se põe da seguinte forma: as chamadas "liberdades democráticas", operacionalizadas segundo uma lógica burguesa, cedem lugar ao princípio de uma disciplina partidária rígida, baseada em uma divisão hierárquica do trabalho partidário, segundo os "diferentes níveis" de consciência de classe.

[...] a coesão organizacional do partido é essencialmente uma hierarquia entre dirigentes e funcionários, fixada numa divisão mecanizada do trabalho. (A aplicação errada e constante de teorias incorretas leva, inevitavelmente, à destruição do partido, mas isso é uma outra questão). 0 caráter eminentemente prático da organização comunista, sua essência como partido de luta, pressupõe, por um lado, uma teoria correta, já que, do contrário, tal organização fracassaria rapidamente com as consequiências de uma teoria errada; por outro, essa forma de organização conduz e reproduz o discernimento teórico correto quando eleva de maneira consciente e em termos organizacionais a sensibilidade da forma de organização para as conseqüências de uma atitude teórica (LUKÁCS, 2003c, p. 575). 
Ficando apenas com essa citação, importa-nos questionar se a própria divisão hierárquica do trabalho partidário não condiciona a uma prática essencialmente capitalista, a uma divisão taylorista entre trabalho intelectual e execução? Ou ainda, entre a intelligentsia partidária (dirigentes) e a base (militantes)?

De acordo com Duarte Pereira (2003, p. 235), ao identificar a consciência imediatamente dada do proletariado enquanto uma falsa consciência, em oposição à verdadeira consciência de classe, que não seria propriamente sua, mas antes, lhe seria atribuída por uma vanguarda intelectual, ou então por outros setores portadores dessa consciência de classe operária fora da própria classe, Lukács resvalou num corte metafísico um tanto quanto arbitrário, em que, na "mais benigna" das possibilidades, o protagonismo político da classe estaria relegado a uma pequena parcela da mesma. Não obstante, sob Stalin na URSS, essa concepção da relação entre a classe operária e sua representação (o Partido) levada ao extremo, institucionalizou-se no que ficou conhecido como sendo a "tradição soviética do marxismo".

Importa-nos ainda considerar, no tocante às "liberdades democráticas", que quando Rosa Luxemburgo defendeu a liberdade enquanto "liberdade dos que pensam de maneira diferente", essa concepção, opostamente ao que pretendeu Lukács, não significaria um retorno ao liberalismo. Luxemburgo, ao contrário, expõe um fundamento imprescindível para a constituição de um "espaço público proletário" (NEGT apud LOUREIRO, 2004, p. 148) como condição primeira para a construção do socialismo. De fato, a autora aposta num certo espontaneísmo, entendendo a construção do socialismo enquanto fruto da ação concreta das massas. Essa tendência da autora aparece de forma bastante expressa no Programa da Liga Spartakus (1918): "A essência da sociedade socialista consiste no seguinte: a grande massa trabalhadora deixa de ser uma massa governada, para viver ela mesma a vida política e econômica na sua totalidade, e para orientála por uma autodeterminação consciente e livre" (LUXEMBURG0, 1991b, p. 102).

0 fato de acreditar que as chamadas "liberdades democráticas" no período revolucionário defendidas por Rosa Luxemburgo condicionariam a uma reação política dos setores "não proletários" (leia-se: "não bolcheviques"), permitiu a Lukács, por fim, identificar um movimento contra-revolucionário em linha reta que se estendeu de Kornilov à Kronstadt (LUKÁCS, 2003b, p. 522).

${ }^{4}$ De acordo com o historiador Daniel Aarão Reis Filho (2002, p. 83-85), a base naval de 
Também é importante ter em conta uma das críticas centrais de Luxemburgo à política bolchevique na Rússia - a oposição entre ditadura e democracia proletária - ou ainda entre "quebrar com mão de ferro a resistência" (LUXEMBURGO, 1991a, p. 89) daqueles que boicotam a revolução, defendendo que "a ditadura socialista [...] não deve recuar perante nenhum meio de coerção para impor ou impedir certas medidas no interesse da totalidade (LUXEMBURGO, 1991a, p. 90)" e a instauração do terror "a mais draconiana justiça militar" (LUXEMBURG0, 1991a, p. 92). Tal critica revela a recusa em enxergar que a linha existente entre "quebrar com mão de ferro a resistência" e o "terror" é muito frágil, ou mesmo inexistente, sendo esta falta de realismo uma característica tipicamente luxemburguiana (LOUREIR0, 2004, p. 146).

Evidentemente, muito longe de pretender encerrar as questões, polêmicas e críticas relacionadas aos conceitos e autores citados ao longo do texto, a problematização que se procura fazer em relação à construção dessa consciência verdadeiramente revolucionária do proletariado, de forma alguma, pode estar cristalizada enquanto díade - ou seja, consciência espontânea ou adjudicada.

A formação da classe trabalhadora, enquanto classe com interesses políticoideológicos conjuntos a partir de um programa político comum (seja ele qual for), é algo que está muito distante do aspecto puramente econômico em si (o lugar ocupado pela classe no sistema de reprodução social). A questão da consciência de classe, abarcando um processo muito mais complexo, perpassa toda uma série de condicionamentos, como os dos campos político, cultural e ideológico. Abordar a questão como mera díade seria não contemplar a realidade social a partir da perspectiva de totalidade.

Concordando com Lukács, o grande mérito da teoria materialista reside no esforço em apreender a realidade enquanto totalidade dialética, o que

Kronstadt contava com uma antiga tradição revolucionária que vinha desde a primeira revolução em 1905. Durante o ano de 1917 manteve uma ativa participação revolucionária, de modo a ser considerado o "que havia de mais revolucionário" na sociedade russa - tanto assim que após a conquista do poder pelo partido bolchevique em Outubro, muitos de seus líderes ascenderam a cargos administrativos no novo governo. Em 1921, o soviete de Kronstadt, em solidariedade com os operários de Petrogrado declararam rebelião contra o governo. Exigiase, em geral, liberdade de manifestação, solidariedade aos operários em greve, sindicatos e eleições livres do controle estatal para os sovietes. Em questão de dias a revolta transformou-se numa revolução rapidamente aniquilada pelo governo. Durante décadas, a história oficial do Partido Comunista Soviético apontou a revolução de Kronstadt como sendo um produto reacionário da contra-revolução internacional. 
necessariamente rompe com a visão parcelar de teorias de outros matizes. Ao identificar, contudo, que a classe operária está dada como tal no terreno da produção, e dessa forma, já tendo uma consciência imediata (uma falsa consciência de classe), Lukács acaba operacionalizando com a distinção hegeliana "em si" e "para si". Nessa perspectiva, a classe proletária já existe, faltando-lhe (para ser revolucionária) apenas a verdadeira consciência de classe, um elemento, lembrando Kautsky, a ser "importado de fora" (BOIT0, 2003, p. 242-243). Desta forma, a classe "em si", já existente no campo das relações materiais de produção, a partir do contato com a vanguarda teórica, passa a ser (num movimento claramente "etapista") classe "para si" - portadora da consciência de classe correta, que contemplaria a totalidade social.

Sem negligenciar a experiência histórica vivida pela esquerda marxista do século XX, naquilo que ficou conhecido como "tradição soviética" do marxismo, grande parte do desafio da esquerda marxista hoje advém da necessidade de dar uma resposta a essa problemática, ou seja, operacionalizar a relação existente entre classe e consciência de classe. Como se chega à consciência de classe, ou antes, como se constrói a classe operária e, nesse sentido, qual deve ser o papel dos intelectuais na formação da classe trabalhadora? Onde está hoje a classe proletária? Como defini-la? Indo além, como pensar o seu papel em relação às demandas das minorias étnicas, ou ainda, quais devem ser suas bandeiras em relação às cada vez mais emergentes questões ambientais? Da resposta a um complexo quadro de questões parece depender o futuro da esquerda revolucionária.

\section{REFERÊNCIAS}

BOITO, Armando. A (difícil) formação da classe operária. In: BOITO, Armando; TOLEDO, Caio Navarro de (Org.). Marxismo e ciências humanas. São Paulo: Xamã, 2003. p. 239-248.

CARDOSO, Felipe Gava. Divisão do trabalho partidário: organização em Lenin. 2007. Dissertação (Mestrado em Sociologia) - Unicamp, Campinas.

REIS FILHO, Daniel Aarão. Uma revolução perdida: a história do socialismo soviético. 2. ed. São Paulo: Fundação Perseu Abramo, 2002.

LOUREIRO, Izabel Maria. Rosa Luxemburg: os dilemas da ação revolucionária. 2. ed. São Paulo: UNESP, 2004. 
Democracia e socialismo em Rosa Luxemburgo. Crítica marxista, Campinas, n. 4, p. 45-57, 1997.

LUKÁCS, George. Rosa Luxemburgo como marxista. In: História e consciência de classe: estudos sobre a dialética marxista. São Paulo: Martins Fontes, 2003a.

- Notas críticas sobre a crítica da revolução russa, de Rosa Luxemburgo. In: LUKÁCS, George. História e consciência de classe: estudos sobre a dialética marxista. São Paulo: Martins Fontes, 2003b.

. Observações metodológicas sobre a questão da organização. In: LUKÁCS, George. História e consciência de classe: estudos sobre a dialética marxista. São Paulo: Martins Fontes, 2003c.

. Prefácio à edição de 1967. In: LUKÁCS, George. História e consciência de classe: estudos sobre a dialética marxista. São Paulo: Martins Fontes, 2003d. LUXEMBURGO, Rosa. Greve de massas, partido e sindicatos. Coimbra: Centelha, 1974.

A revolução russa. In: LUXEMBURG0, Rosa. A revolução russa. Petrópolis: Vozes, 1991a.

. 0 que quer a liga Spartakus? In: LUXEMBURG0, Rosa. A revolução russa. Petrópolis: Vozes, 1991b.

MARX, Karl. 018 brumário de Luís Bonaparte. São Paulo: Abril Cultural, 1978. Coleção Os Pensadores.

PEREIRA, Duarte. Das classes à luta de classes. In: BOITO, Armando; TOLEDO, Caio Navarro de (Org.). Marxismo e ciências humanas. São Paulo: Xamã, 2003. p. 227-238. 